\title{
Study of the genetic organization of the strain Rhizobium leguminosarum bv. trifolii forming a symbiosis with clover Trifolium ambiguum
}

Aksenova T.S., Onishchuk O.P., Kurchak O.N., Andronov E.E., Provorov N.A.

All-Russian Research Institute for Agricultural Microbiology

E-mail: t.aksenova@arriam.ru

Key message. R. leguminosarum bv. trifolii strains are characterized by narrow host specificity. We have identified a strain that forms nodules on several types of clover and studied the genetic organization of its symbiotic region.

Keywords: R. leguminosarum bv. trifolii, T. ambiguum, $N_{2}$-fixing symbiosis

Rhizobium leguminosarum bv. trifolii (Rlt) strains are characterized by narrow specificity to host plants and are able to form nodules only on species of the Trifolium genus. These rhizobia have a high specificity of interaction with different types of clover. The highest selectivity to microsymbionts is inherent to clover $T$. ambiguum, the Caucasian endemic specie. It has been shown that rhizobia, that are capable to form an effective symbiosis with $T$. ambiguum, usually do not form symbiosis with $T$. repens and $T$. pratense and vice versa (Beauregard et al. 2004). The genetic basis of this specificity is poorly understood, but it is known that in other rhizobia species, symbiotic genes, which evolution is controlled by host plants, are responsible for this function. In the present work, analyzing the collection of strains isolated from the soil of the Leningrad Region (Vyritsky District), strain 23B, which forms pinkish nodules on T. ambiguum, was detected in a micro-vegetation experiment using trap plants $T$. repens and $T$. pratense. Like the other studied strains, this strain formed pink nodules on the widespread types of clover - T. repens, $T$. pratense, $T$. hybridum. Total DNA was isolated from five Rlt strains and genomewide sequencing (Oxford Nanopore) was performed. It was revealed that the size of the entire symbiotic cluster located on Sym-plasmids and including the nodXONMLEFDABCIJ, nifBA, fixXCBA, nifHDKEN, and fixNOQPGHIS operons, is $72643 \pm 643 \mathrm{bp}$ for the strains incapable of symbiosis with T. ambiguum, meanwhile as in strain $23 \mathrm{~B}$, capable of forming nodules on T. ambiguum, the size of the symbiotic cluster was $29016 \mathrm{bp}$. According to preliminary data, this difference is associated with reduced (almost three times) intergenic distances in the symbiotic region of strain 23B. The data obtained allow us to begin to identify genetic factors that determine the specificity of clover rhizobia in relation to Trifolium ambiguum. The equipment of the Center for Genomics, Proteomics and Cell Biology, ARRIAM was used. Supported by the Russian Science Foundation, grant 19-16-00081.

\section{Изучение генетической организации штамма Rhizobium leguminosarum bv. trifolii, образующего симбиоз с клевером Trifolium ambiguum}

Аксенова Т.С., Онищук О.П., Курчак О.Н., Андронов Е.Е., Проворов Н.А. ВНИИ сельскохозяйственной микробиологии, Санкт-Петербург, Россия

\begin{abstract}
Аннотация. Ризобии вида R. leguтinosarum $b v$. trifolii характеризуются узкой хозяйской специфичностью. Нами выявлен штамм, образующий клубеньки на Trifolium ambiguит и изучена генетическая организация его симбиотического региона.
\end{abstract}

Ключевые слова: R. leguminosarum bv. trifolii, T. атbiguит, хозяйская специфичность, азотофиксируюший симбиоз

Штаммы Rhizobium leguminosarum bv. trifolii характеризуются узкой специфичностью по отношению к растениямхозяевам и способны формировать клубеньки только на видах рода Trifolium. Для этих ризобий характерна высокая специфичность взаимодействия с разными видами клевера. Наибольшей избирательностью по отношению к микросимбионтам характеризуется клевер T. ambiguum, который является эндемиком Кавказа. Было показано, что ризобии, способные формировать эффективный симбиоз с T. ambiguum, обычно не образуют симбиоза с $T$. repens и $T$. pratense и наоборот (Beauregard et al. 2004). Генетические основы такой специфичности мало изучены, но известно, что у других видов ризобий за эту функцию отвечают симбиотические гены, эволюция которых контролируется растениями-хозяевами. В настоящей работе анализируя коллекцию штаммов, выделенных из почвы Ленинградской области (Вырицкий район), в микровегетационном опыте с использованием растений-ловушек T. repens и T. pratense был выявлен штамм 23В, образующий розоватые клубеньки на T. ambiguum. Этот штамм формировал, как и другие изученные штаммы, розовые клубеньки на широко распространенных видах клевера - T. repens, T. pratense, T. hybridum. Из пяти штаммов Rlt была выделена тотальная ДНК и проведено полногеномное секвенирование (Охford Nanopore). Выявлено, что размер всего симбиотического кластера, находящегося на Sуm-плазмидах и включающего опероны nodXONMLEFDABCIJ, nifBA, fixXCBA, nifHDKEN и fixNOQPGHIS, составляет у штаммов, не способных к симбиозу с $T$. ambiguum, $72643 \pm 643$ п.о., в то время как у штамма 23В, способного формировать клубеньки на $T$. ambiguum, размер симбиотического кластера составил 29016 п.о. Согласно предварительным данным, это различие связано с уменьшенными (почти в три раза) межгенными расстояниями в симбиотическом регионе у штамма 23 В. Полученные данные позволяют приступить к выявлению генетических факторов, определяющих специфичность ризобий клевера по отношению к Trifolium ambiguum.

Работа выполнена с использованием оборудования ЦКП «Геномики, протеомики и клеточной биологии» ВНИИСХМ, при финансовой поддержке РФФИ в рамках научного проекта № 18-34-00839 и РНФ, грант 19-16-00081. 